\title{
Student Cognitive Activities in Biogeochemical Cycle Learning Using Modeling Example
}

\author{
Dewi Susanti ${ }^{1,}$ Adi Rahmat ${ }^{1, *}$ Amprasto $^{1}$ \\ ${ }^{1}$ Department of Biology Education, Universitas Pendidikan Indonesia, Indonesia \\ *Corresponding author. Email: adirahmat@upi.edu
}

\begin{abstract}
The research aims to get information on student cognitive activities in biogeochemical cycle learning using modeling example. The research method uses a quasi-experiment. Cognitive activities are obtained by recording students' verbal data during the biogeochemical cycle of learning. Students' verbal data were analyzed and categorized into types of cognitive activity according to the think-aloud protocols (TAPs) method. Students who learn using modeling examples can bring up cognitive activities in a higher category than students who do not learn using modeling examples. Students' cognitive activities can be stimulated using modeling examples. Cognitive activities that appear when students learn the biogeochemical cycle are prior knowledge activation (K1), identifying (K2), interpreting symbols (K3), comparing (K4), making hypotheses (K5), inferring knowledge (K6), and elaborating knowledge (K7).
\end{abstract}

Keywords: Cognitive activities, Biogeochemical cycle, Modelling example

\section{INTRODUCTION}

The biogeochemical cycle is a cycle of elements C (carbon), $\mathrm{O}$ (oxygen), $\mathrm{N}$ (nitrogen), $\mathrm{S}$ (sulfur), and $\mathrm{P}$ (phosphor) that involves interactions between biotic and abiotic components in the atmosphere, biosphere, hydrosphere, geosphere, and anthroposphere [1]. The biogeochemical cycle consists of the water, carbon, nitrogen, sulfur, and phosphorus cycles. Biogeochemical cycle material in high school is studied in class $\mathrm{X}$ semester 2. Basic Competencies regarding biogeochemical cycle material, namely $\mathrm{KD}$ 3.10 Analyzing ecosystem components and interactions between these components, and KD 4.10 Presenting works that show interactions between ecosystem components (food webs, biogeochemistry cycles) [2].

Teachers in the school where this research was conducted revealed that there were still many students who failed to describe the biogeochemical cycle, especially the carbon and nitrogen cycle. Students still experience failures in solving problems in complex process diagrams (carbon and nitrogen cycles), and the ability to solve process diagram problems is related to students' prior knowledge, spatial abilities, and student working memory capacity [3]. In learning the carbon cycle, students identify several components of the carbon cycle, tend to track carbon atoms exclusively at the organism level, and experience failure to identify organic carbon compounds, especially during the process in which carbon compounds are transformed [4]. Students often have misconceptions about the processes involved in the carbon cycle, and cannot often think at different levels of biological organization, which is necessary to explain complex biological phenomena in detail [5].

When students understand the biogeochemical cycle diagram there is cognitive activity involved. Cognitive activity is a variety of cognitive activities that involve mental activities that occur in working memory when a person performs a thought process. The cognitive activity has a major contribution to building students' understanding when studying a diagram [6]. Based on the complexity of the information contained in the diagrams and the cognitive activities that occur, a learning approach is needed that can stimulate student cognitive activity. One approach that can be applied is modeling examples. In learning with modeling examples, students fully complete the assignments given and present them [7]. Learning with modeling examples can improve the ability of students to process and describe the information presented and evaluate it [8]. 


\section{METHOD}

The research was a quasi-experiment. The experiment group used a modeling example, and the control group used video observation. The respondent of this study consisted of 60 students in senior high school (30 student experiment groups, and 30 student control groups). The biogeochemical studied consists of the water cycle, nitrogen cycle, and carbon cycle. Students are given examples of the water cycle, and the nitrogen cycle, then students make a model of the carbon cycle. Cognitive activities are obtained by recording students' verbal data during the biogeochemical cycle of learning. Students' verbal data were analyzed and categorized into types of cognitive activity according to the think-aloud protocols (TAPs) method. Verbal data were obtained using audio and video recording.

The measurement of cognitive activities was carried out three times. The first measurement was during the water cycle learning, the second measurement was during the nitrogen cycle learning, and the third measurement was during the carbon cycle learning. The total cognitive activities of students during the learning cycle of water, nitrogen, and the carbon cycle is cumulative average of the frequency and accuracy of cognitive activities. Cognitive activity values are obtained from the sum of the frequency and accuracy score.

\section{RESULT AND DISCUSSION}

Cognitive activity is a variety of cognitive activities that involve mental activities that occur in working memory when a person performs a thought process [6]. In learning biogeochemical cycles using modeling examples found seven types of cognitive activity, namely prior knowledge activation (K1), identifying (K2), interpreting symbols (K3), comparing (K4), making hypotheses (K5), inferring knowledge (K6), and elaborating knowledge (K7). The types of cognitive activity that occur are similar to that found by Cromley et al. [6], when students studied the $\mathrm{T}$ cell diagram, there were four types of cognitive activity, namely activating knowledge, hypotheses, inferring knowledge, and elaborating on knowledge. However, in his research, there was no identification and comparison of cognitive activity.

The types of cognitive activity that emerged in this study were similar to those found by Kragten et al. [9], and Brandstetter et al. [10]. When students read the diagram of the formation of stomach acid, neurotransmitters, and metabolic processes, five types of cognitive activity were found, namely activation of knowledge, identifying detailed images, understanding symbols, comparing, and making alternative hypotheses [9]. There are three cognitive activities related to pictorial information when students read circulatory system diagrams and patellar reflexes, namely remembering and expressing initial knowledge, identifying the structure of names and types, and concluding by connecting information. Types of cognitive activity carried out by Brandstetter et al. [10] found in this study. But the difference, in the study of Brandstetter et al. [10] did not find any cognitive activities that compare, hypothesize, and deciphering knowledge.

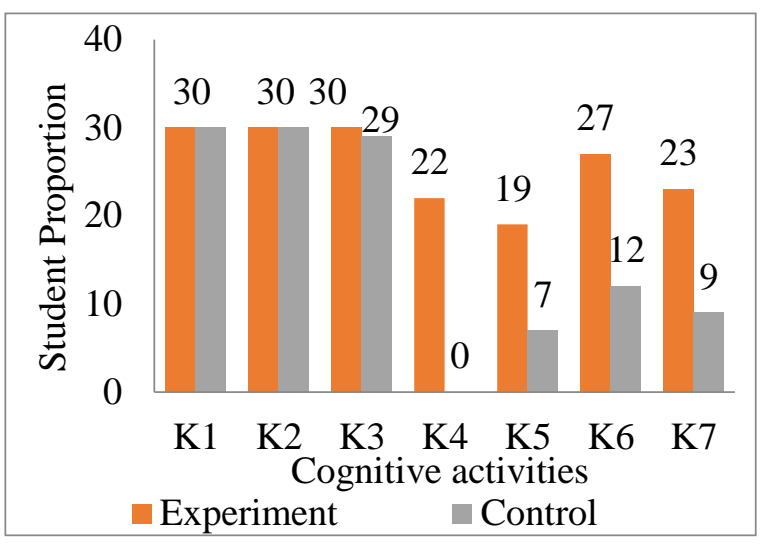

Figure 1 The proportion of students who bring up cognitive activities.

All students in the experimental class and the control class increase their cognitive activity to prior knowledge activation (K1) and identify (K2). None of the control class students gave rise to a cognitive activity comparing (K4). Control class students have not been able to compare the information on the water, nitrogen, and carbon cycles. The number of students in the experimental class who gave rise to cognitive activities interpreting symbols (K3), comparing (K4), making hypotheses (K5), inferring knowledge (K6), and elaboration (K7) was more than the control class students (Figure 1). In the experimental class learning using modeling examples, cognitive activity comparing (K4) was found during the learning of the water cycle, nitrogen cycle and, carbon cycle. Cognitive activity comparing was found at the example of the water cycle, nitrogen cycle, and when students explore and design a carbon cycle model. Students learning by modeling examples can generate all kinds of cognitive activities.

The frequency of cognitive activity that appeared in the experimental class had a higher number and mean than the control class (Table 1). There is a difference in the average frequency of occurrence for each cognitive activity between the experimental class and the control class as much as 42 frequency. Thus, 
Table 1. Frequency and accuracy for each type of cognitive activity

\begin{tabular}{|c|c|c|c|c|c|c|}
\hline \multirow[t]{3}{*}{ CA } & \multirow{2}{*}{\multicolumn{2}{|c|}{ Frequency }} & \multicolumn{4}{|c|}{ Accuracy } \\
\hline & & & \multicolumn{2}{|c|}{$\begin{array}{l}\text { Experiment } \\
\text { Class (EC) }\end{array}$} & \multicolumn{2}{|c|}{$\begin{array}{l}\text { Control } \\
\text { Class } \\
\text { (CC) }\end{array}$} \\
\hline & EC & CC & A & NA & $\mathbf{A}$ & NA \\
\hline $\mathrm{K} 1$ & 98 & 72 & 92 & 6 & 57 & 15 \\
\hline $\mathrm{K} 2$ & 90 & 58 & 88 & 2 & 49 & 9 \\
\hline K3 & 82 & 58 & 82 & 0 & 56 & 2 \\
\hline K4 & 35 & 0 & 34 & 1 & 0 & 0 \\
\hline K5 & 72 & 11 & 57 & 15 & 9 & 2 \\
\hline K6 & 91 & 20 & 76 & 15 & 17 & 3 \\
\hline K7 & 57 & 14 & 56 & 1 & 11 & 3 \\
\hline$\Sigma$ & 525 & 233 & 485 & 40 & 199 & 34 \\
\hline $\bar{X}$ & 75 & 33 & 69 & 5 & 28 & 4 \\
\hline SE & 8.4 & 10.7 & 7.9 & 2.5 & 9.2 & 1.9 \\
\hline
\end{tabular}

CA: Cognitive Activities, EC: Experiment Class, CC: Control Class, A: Accurate, NA: Not Accurate.

students in the experimental class who learn by modeling examples can bring up each type of cognitive activity with a higher frequency of occurrence compared to students in the control class. Learning using modeling examples can be effective for complex tasks in an unstructured domain [11]. Not all types of cognitive activity that appear in the experimental class and control class students are accurate. In experimental class students, all types of cognitive activity were found to be accurate in interpreting symbols (K3). These results illustrate that during the process of interpreting symbols (K3), the experimental class students were able to process the information on symbols in the biogeochemical cycle. Examples of symbols that exist in a biogeochemical cycle are one of the arrows symbolizing the sequence of processes in that cycle. However, the control class students found two inaccurate activities to interpret symbols (K3). Control class students still have errors in processing the information symbols in the biogeochemical cycle.

Cognitive activity inferring knowledge (K6) when studying the biogeochemical cycle with modeling examples appeared ninety-one times with more accuracy than the control class (Table 1). When studying the biogeochemical cycle, students can deduce the knowledge they have acquired from the water, nitrogen, and carbon cycles. The inference is a statement that includes the relationship between processes that are not presented literally [12]. The inference is an important part of understanding graphical representations $[6,13,14]$. This is supported by Kragten et al. [9] which states that inference is an important activity for learning. Students who have good inference abilities will be able to infer new knowledge with the knowledge they have [12]. This is evident from what was found in this study, namely the frequency of cognitive activity elaborating on knowledge more and more accurately than the control class (Table 1).

In the experimental class, cognitive activity in elaborating knowledge (K7) appeared more than in the control class (Table 1). This shows that by modeling examples, students can deduce the knowledge they get about the biogeochemical cycle and are supported by their initial knowledge. Unlike the case with the control class who used video observation, the cognitive activity that most often appeared was a cognitive activity which prior knowledge activation (K1) (Table 1). This means that the control class students still dominantly use their initial knowledge when studying the biogeochemical cycle. Students in the experimental class in elaborating knowledge (K7) found only one inaccurate statement. Thus, students can conclude the knowledge obtained with the support of their initial knowledge well. Experimental class students have the appearance of cognitive activity to prior knowledge activation (K1), and identify (K2) inaccurately is lower than that of control class students (Table 1). These results indicate that in processing preliminary knowledge information and identifying biogeochemical cycles, students who learn with modeling examples do better than the control class.

When studying the biogeochemical cycle using modeling examples, students were able to activate their initial knowledge with the greatest frequency and accuracy (Table 1). The stages in learning with modeling examples are preceded by activating initial knowledge [15]. This shows that modeling examples can activate students' initial knowledge which is important to support the emergence of other cognitive activities. This is evidenced by the emergence of all types of cognitive activities up to the highest level, namely elaborating knowledge (K7) (Table 1). Prior knowledge has been identified as an important factor in understanding diagrams [16]. Early knowledge can influence the selection of information, interpretation, and conclusion from the diagram [17]. The frequency results found in the experimental class meant that 
students began to be activated with their initial knowledge of the biogeochemical cycle. Students dig up the initial knowledge they already have which is in long-term memory. Then after being activated, students can identify biogeochemical cycles. In learning with the modeling example approach, students can identify process components and not processes in the water cycle, nitrogen cycle, and carbon cycle.

When studying the water cycle, the dominance of students' cognitive activities is still at the use of their initial knowledge. However, when given examples of the nitrogen cycle, students began to be able to generate cognitive activities comparing, hypothesizing, inferring knowledge, and elaborating on knowledge. At the time of learning the carbon cycle, there are steps to explore, design, create, and present a model that helps students bring out their cognitive activities. Thus, seven types of cognitive activity appear at this stage with a high number of students and frequency. Students who learn with modeling examples experience an increase in the frequency of cognitive activity and the frequency is higher than students who do not learn with modeling examples.

Students have started to be trained to infer and elaborate knowledge so that the initial knowledge they have is used to support the knowledge they acquire during learning. The experimental class students concluded that there are five processes involved in the carbon cycle, namely respiration, photosynthesis, consumption, decomposition, and combustion. This conclusion was supported by the elaboration of the students' knowledge which was expressed, the student concluded the process of the carbon cycle with the support of his initial knowledge of the food chain, processes that exist in the soil so that fossil fuels can be produced.

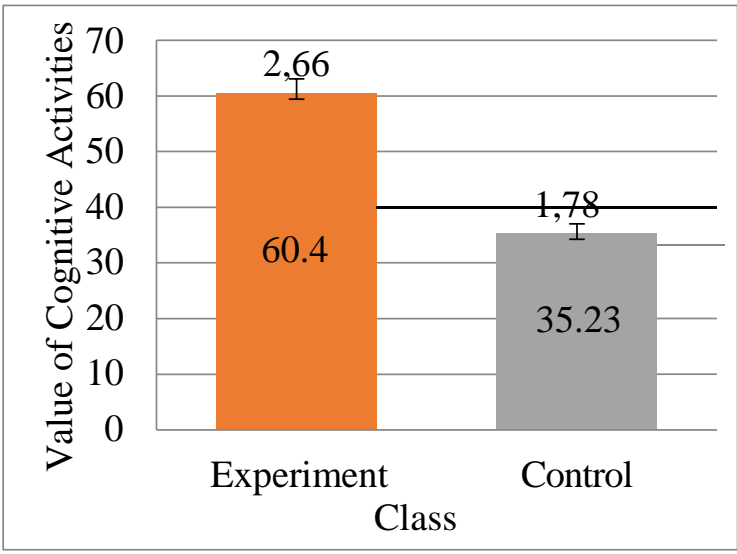

Figure 2 The value of cognitive activity of students in experiment and control class.
Students who learn with modeling examples in studying the biogeochemical cycle, get a higher category of cognitive activity scores than students who do not learn with modeling examples (figure 2). Students can process the information in the biogeochemical cycle starting from the process of activating initial knowledge to the process of elaborating knowledge. In learning biogeochemical cycles using modeling examples, students explore examples, make designs and models, and present the model in groups. Based on these activities, there is the interaction between students and students, and students and teachers. Students argue, respond, and question and answer. Example-based learning is studied from a cognitive and social-cognitive perspective.

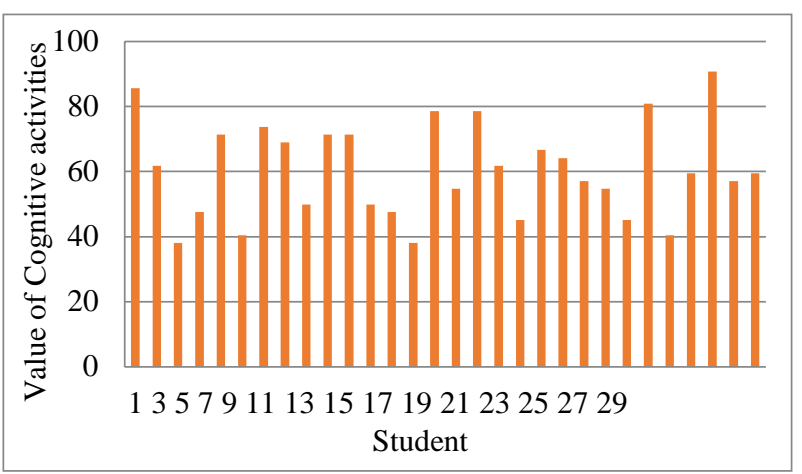

Figure 3 The value of cognitive activity of each student in the experimental class.

In the experimental class, it was found that student 28 had the highest cognitive activity score compared to other students (Figure 3). The value of cognitive activity obtained by students was included in the very high category. Apart from student 28, two other students obtained very high scores for cognitive activity, namely students 1 and 25 . Based on these results it showed that students 1,25 , and 28 were very high in processing information in the biogeochemical cycle starting from the activating process. Prior knowledge activation (K1) to elaborating knowledge (K7).

Student 28 stated that the processes involved in the water cycle were evaporation, transpiration, condensation, precipitation, infiltration, and percolation. The water cycle also involves water, clouds, wind, mountains, plants, and soil. The processes involved in the nitrogen cycle are fixation, consumption, excretion, ammonification, nitrification, absorption, and denitrification. The processes that occur in the nitrogen cycle are related to living things that do it, namely bacteria, humans, animals, plants, 
fungi, phytoplankton, fish, and algae. Humans, animals, and plants cannot directly absorb nitrogen from the air. The fixation is carried out by Rhizobium bacteria in the roots of legumes, Azotobacter in the soil, and Cyanobacteria in the water. In the carbon cycle, plants have chlorophyll so they can carry out photosynthesis. This photosynthetic process will later produce oxygen and energy which will be used by plants, and oxygen will be used by humans and animals for the respiratory process. Carbon dioxide is not only produced from the breathing process but also the combustion process in vehicles.

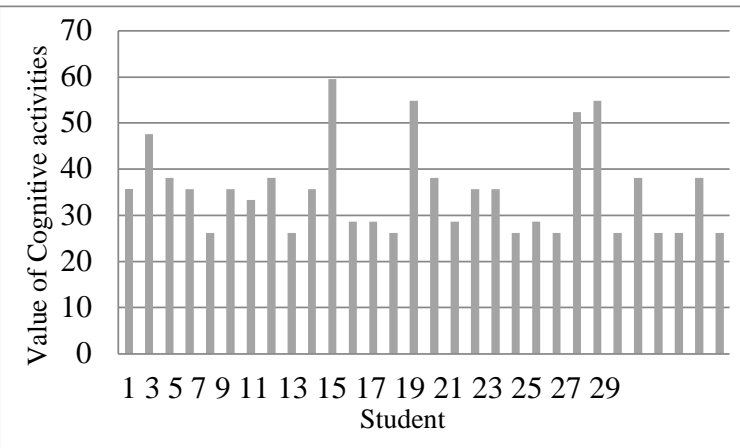

Figure 4 The value of cognitive activity of each student in the control class.

None of the control class students' cognitive activity scores were in the very high category and the high category. Student 11 gets the highest cognitive activity score, but this score is only included in the moderate category. Also, there were students 2, 15, 23, and 24 who had moderate cognitive activity scores (Figure 4). These results indicate that the student is processing the information in the biogeochemical cycle, starting from the process of prior knowledge activation (K1) to elaborating knowledge (K7). These students did not generate cognitive activity comparing (K4), meaning that students could not compare the information contained in the water, nitrogen, and carbon cycles. The cognitive perspective focuses on working examples, and the social-cognitive perspective focuses on modeling examples. The social-cognitive perspective refers to Bandura's [18] social-cognitive theory. Based on the theory, learning occurs by observing the appearance of the model. In the example step of the water cycle, students compare that the evaporation process is different from the transpiration process. The transpiration process plays a role in plants, while evaporation is directly from the water.

The student can already compare that there is a difference between evaporation and transpirationeven though both are evaporation processes. When given an example of the nitrogen cycle, students in the experimental class compared that the nitrogen cycle involved different processes from the water cycle. When students explore and design a carbon cycle model, students compare that the processes involved in the carbon cycle are different from the water and nitrogen cycle. Based on the statement expressed, students in the experimental class were able to compare that there were differences in the processes involved in the water, nitrogen, and carbon cycles. Besides, students in the experimental class were not patterned, which meant they understood the concepts in the water, nitrogen, and carbon cycles.

Table 2. Statistic test of cognitive activity data of experiment and control class students

\begin{tabular}{|c|c|c|}
\hline \multirow{2}{*}{ Statistic test } & \multicolumn{2}{|c|}{ Class } \\
\cline { 2 - 3 } & Experiment & Control \\
\hline Mean & 60.40 & 35.23 \\
\hline Median & 59.50 & 35.70 \\
\hline $\begin{array}{c}\text { Normality test } \\
0.490 \\
(p>0,05)\end{array}$ & $0.000(p<0.05)$ \\
\hline $\begin{array}{c}\text { Homogeneity } \\
\text { Test }\end{array}$ & $0.014(p<0.05)$ \\
\hline $\begin{array}{c}\text { Mann-Whitney } \\
\text { test }\end{array}$ & \multicolumn{2}{|c|}{$0.000(p<0.05)$} \\
\hline
\end{tabular}

The results of differences in cognitive activity scores of experimental class students and control class students were strengthened by conducting statistical tests. The results of the normality test showed that the distribution of the cognitive activity value data of the experimental class students was normal ( $p>0.05$ ), while the distribution data of the cognitive activity values of the control class students were not normal $(\mathrm{p}<0.05)$ (Table 2), and the control class variance was not homogeneous $(\mathrm{p}<0.05)$. Because the data variance was not homogeneous, the Mann-Whitney test was performed. The Mann-Whitney test shows that is a significant difference in the median value of the cognitive activity of the experimental class and control class students $(\mathrm{p}<0.05)$ (Table 2).

The types of cognitive activity that often appear in the findings of this study (Table 1) are the same as Cromley et al. [6], in their research, it was found that the most frequent occurrence was knowledge-inferring activity. This is the same as research conducted by Ayunda [19] was found that the cognitive activity that most often arose when students studied the photosynthetic process, namely the activity of interference with a percentage of $30 \%$. However, it is 
different from what Raksabrata [20] found when studying plant life cycle diagrams, the cognitive activity that most often arises is the activity of identifying detailed images. The similarities and differences in the emergence of cognitive activities show that using modeling examples can lead to cognitive activities ranging from low levels (activating initial knowledge) to high levels (inferring knowledge) (Table 1). Cognitive activity is based on cognitive abilities in general, namely the ability to memorize and apply initial knowledge, as well as the ability to express reasons in a relationship [21,22].

\section{CONCLUSION}

Based on the results, can be concluded that students who learn using modeling example can bring up cognitive activity in a higher category than students who do not learn using modeling example. Students' cognitive activities can be stimulated using modeling examples. Cognitive activities that appear when students learn the biogeochemical cycle are prior knowledge activation (K1), identifying (K2), interpreting symbols (K3), comparing (K4), making hypotheses (K5), inferring knowledge (K6), and elaborating knowledge (K7).

\section{ACKNOWLEDGMENTS}

The author would like to thanks the school where the research was conducted and the lecturer Biology Education in Universitas Pendidikan Indonesia, Department of Biology Education who have helped guide the research process.

\section{REFERENCES}

[1] H. Rodhe, 4 Modeling Biogeochemical Cycles, Internasional Geophysics 50 (1992) 55-72. DOI: https://doi.org/10.1016/S0074-6142(08)62687$\underline{X}$

[2] Ministry of Education and Culture, Syllabus for Biology Subjects High School or Madrasah Aliyah (SMA / MA), Jakarta, 2016.

[3] M. Kragten, W. Admiraal, G. Rijlaarsdam, Students' Ability to Solve Process-Diagram Problem in Secondary Biology Education, Journal of Biological Education 49 (2014) 1-13. DOI:

https://doi.org/10.1080/00219266.2014.888363

[4] K. Düsing, R. Asshoff, M. Hammann, Students' Conceptions of The Carbon Cycle: Identifying and Interrelating Components of The Carbon Cycle and Tracing Carbon Atoms Across The Levels of Biological Organisation, Journal of
Biological Education 53(1) (2018) 110-125.

DOI:

https://doi.org/10.1080/00219266.2018.1447002

[5] M. Wierdsma, M.C. Knippels, B. van Oers, K. Boersma, Recontextualising Cellular Respiration in Upper Secondary Biology Education: Characteristics and Practicability of A Learning and Teaching Strategy, Journal of Biological Education 50(3) (2016) 239-250. DOI: https://doi.org/10.1080/00219266.2015.1058842

[6] G. Cromley, S. Hogan, L. Dubas, Cognitive Activities in Complex Science Text and Diagrams, Contemporary Educational Psychology 35(1) (2010) 59-74. DOI: https://doi.org/10.1016/j.cedpsych.2009.10.002

[7] B.M. McLaren, T. van Gog, C. Ganoe, M. Karabinos, D. Yaron, The Efficiency of Worked Examples Compared to Erroneous Examples, Tutored Problem Solving, and Problem Solving in Computer-Based Learning Environments, Computers in Human Behavior 55 (2016) 87-99. DOI: https://doi.org/10.1016/j.chb.2015.08.038

[8] M.A.H. Braaksma, G. Rijlaarsdam, H. Van den Bergh, B.H.A.M Van Hout-Wolters, What Observational Learning Entails: A Case Study, Journal of L1 Educational Studies in Language and Literature 6 (2006) 31-62.

[9] M. Kragten, W. Admiraal, G. Rijlaarsdam, Students' Learning Activities While Studying Biological Process Diagrams, International Journal of Science Education 37(12) (2015) 1915-1937. DOI: https://doi.org/10.1080/09500693.2015.1057775

[10] M. Brandstetter, A. Sandmann, C. Florian, Understanding Pictorial Information in Biology: Students' Cognitive Activities and Visual Reading Strategies, International Journal of Science Education 39(9) (2017). DOI: https://doi.org/10.1080/09500693.2017.1320454

[11] B.E Baum, J.J. Gray, Expert Modeling, SelfObservation Using Videotape, and Acquisition of Basic Theraphy Skills, Journal of Professional Psychology: Research and Practice 23 (1992) 220-225. DOI: https://doi.org/10.1037/07357028.23.3.220

[12] M. Chi, Self-explaining expository texts: The dual process of generating inferences and repairing mental models, in: R. Glaser (Ed.), Advances in Instructional Psychology, vol. 5, Arizona State University (ASU), Hillsdale, New Jersey, 2000, pp. 161-238.

[13] M. Hegarty, Multimedia Learning about Physical 
Systems, M Hegarty \& R E Mayer (Eds), The Cambridge handbook of multimedia learning, Cambridge University Press, 2005.

[14] S. Kriz, M. Hegarty, Top-Down and Bottom-Up Influences on Learning from Animations, International Journal of Human-Computer Studies 65(11) (2007) 911-930. DOI: https://doi.org/10.1016/j.ijhcs.2007.06.005

[15] J. Frerejean, J.L.H. van Strien, P.A. Kirschner, S. Brand-Gruwel, Effects of A Modelling Example for Teaching Information Problem Solving Skills, Journal of Computer Assisted Learning (2016) 1-13.

[16] M.P. Cook, G. Carter, E.N. Wiebe, The Interpretation of Cellular Transport Graphics by Students with Low and High Prior Knowledge, International Journal of Science Education 30(2) (2008) 239-261. DOI: https://doi.org/10.1080/09500690601187168

[17] M.P. Cook, Visual Representations in Science Education: The Influence of Prior Knowledge and Cognitive Load Theory on Instructional Design Principles, Science Education 90(6) (2006) 1073-1091. DOI: https://doi.org/10.1002/sce.20164

[18] A. Bandura, Social Learning Theory, Prentice Hall, 2007.

[19] T.R. Ayunda, A. Rahmat, S. Diana, Understanding photosynthesis videos: Students' visual-spatial ability and cognitive activities in senior high school, in: AIP Publishing, College Park, Maryland, 2019. DOI: https://doi.org/10.1063/1.5115713

[20] M.R. Raksabrata, The relation of studen's diagram comprehension, knowledge and cognitive activities while studying mosses metagenesis diagram, Journal of Physics Conference Series, in: IOP Publishing, Bristol 2019, pp. 022105. DOI:https://doi.org/10.1088/17426596/1157/2/0 $\underline{22105}$

[21] S. Ainsworth, DeFT: A Conceptual Framework for Considering Learning with Multiple Representations, Learning and Instruction 16(3) (2006) 183-198. DOI: https://doi.org/10.1016/j.learninstruc.2006.03.00 1

[22] W. Schnotz, Integrated Model of Text and Picture Comprehension in R E Mayer (Ed.), Cambridge handbooks in Psychology, The Cambridge handbook of multimedia learning, Cambridge University Press, 2014. 